\title{
DESCRIPTION OF M. KASTNER'S NEW MUSICAL INSTRUMENT, THE PYROPHONE.*
}

\author{
BY M. DUNANT.
}

Sound is, in general, according to natural philosophers, a sensation excited in the organ of hearing by the vibratory movement of ponderable matter, whilst this movement can be transmitted to the ear by means of an intermediate agent. - Sound, properly called musical sound or tone, is that which produces a continuous sensation, and of which one can appreciate the musical value. Noise is a sound of too short a duration to be appreciated well, as the noise of a cannon, or else it is a mixture of confused and discordant sounds like the rolling of thunder. For a single sound to become a musical sound, that is to say, a tone corresponding to one of the intonations of the musical scale, it is necessary that the impulse and, consequently, the undulations of the air should be exactly similar in duration and intensity, and that they should return after equal intervals of time. In its change to the musical state, however dull and confused the noise may be, it becomes clear and brilliant. Like the diamond, after having been polished and cut according to the rules of art, it has the brilliancy for the ear which the former has for the eye. This is what takes place in singing flames. Very imperfect in its beginning, hoarse, roaring, or detonating, it does not come nearer the musical sound, properly so called in the chemical harmonica, as it is termed, still, by means of reiterated trials the sound of the single flame in the tube, the lumen philosophicum, as it is elsewhere called, can it be musically produced in every case?

It has long been known that a flame traversing a glass tube under a certain pressure produces a musical sound. The eminent savant, Professor Tyndall, to whom the greater part of the deep questions in physics are no mysteries, has studied singing flames, but it must be admitted that singing flames have only penetrated into the dominion of art in consequence of the discovery made by $\mathbf{M}$. Frederic Kastner of the principle which allows of their being tuned and made to produce at will all the notes of the musical scale, to stop the sound

* A paper read before the Society of Arts, February 17 th, 1875 . 
instantaneously and mechanically; as in keyed instruments the sound is regulated and subdued as desired. It is thus that the modest harmonica chimique, lumen philosophicum of natural philosophers has, in the pyrophone, attained to the character of a real musical instrument; this happy result supports the remark that the observation in nature of the phenomenon of sound may conduct man, if not exactly to the invention of music, at least to endow the art with resources which increase its power. The sound of the pyrophone may truly be said to resemble the sound of a human voice, and the sound of the Eolian harp; at the same time sweet, powerful, full of taste, and brilliant; with much roundness, accuracy, and fullness; like a human and impassioned whisper, as an echo of the inward vibrations of the soul, something mysterious and indefinable; besides, in general, possessing a character of melancholy, which seems characteristic of all natural harmonies. The father of this young philosopher, a member of L'Institut de France, and a learned author, who died in 1867, treating on cosmic harmonies, insists on this peculiarity :-

"The harmonies of nature," said he, "which in their terrible grandeur as well as in their ineffable sadness, have ever charmed the philosopher, poet and artist, are most often stamped with a character of vague melancholy, from the influence of which the mind cannot escape. It is especially when the noise of the world is hushed that these powerful harmonies produce the most overpowering and poetical effects."

It characterizes, for example, the sound of the echo, the sound called harmonics, and many others which are included in the range of musical tones, defined further on under the name of chemical and sympathetic music. We have the most remarkable examples of these in the sound of the Eolian harp. Science, as well as philosophy, poetry, and musical art, is interested in the further study of these sounds. In Germany, Goethe and Novalis, in France, Jean Paul, and many others, have eagerly appreciated the bond which unites natural harmonies to the most elevated instincts, and to the most ideal aspirations of the human soul.

Professor Tyndall has recognised the fact that in order to render a flame musical, it is necessary that its volume be such that it should explode in unison with the undulations of the fundamental note of the tube, or of one of its harmonics. He also asserts that when the volume of the flame is too great, no sound is produced; he demon- 
strates it, by increasing the flow of gas. Professor Tyndall has also called attention to this fact, that in order that a flame may sing with its maximum of intensity, it is necessary that it should occupy a certain position in the tube. He shows this by varying the length of the tube over the flame, but he does not specify the proportions which must exist between the flame and the tube for obtaining this maximum intensity of sound. M. Kastner's merit is in having shown that when two or several flames are introduced into a tube, they vibrate in unison, and produce the musical maximum of sound when they are placed one-third the length of the tube, and if these two flames are brought in contact, all sound ceases directly, a phenomenon M. Kastner demonstrates to be caused by the interference of sounding flames. Here is a question, lately scarcely thought of, of which M. Frederic Kastner has determined the laws, at the same time making a most remarkable application of them in creating an instrument which reminds one of, and may be mistaken for the sound of the human voice.

A very simple mechanism causes each key to communicate with the supply pipes of the flames in the glass tubes. On pressing the keys, the flames separate and the sound is produced. As soon as the fingers are removed from the keys, the flames join, and the sound ceases immediately. These new experiments made by M. Kastner upon singing flames should cause all makers of musical instruments to turn their attention to inventions connected with sound. If two flames of suitable size be introduced into a glass tube, and if they be so disposed that they reach one-third of the tube's height, measured from the base, the flames will vibrate in unison. This phenomenon continues as long as the flames remain apart, but the sound ceases as soon as the-two flames are united. If the position of the flames in the tube is varied, still keeping them apart, it is found that the sound diminishes while the flames are raised above the one-third until they reach the middle point, where the sound ceases. Below this point the sound increases down to one-fourth of the tube's length. If at this latter point the flames are brought together, the sound will not cease immediately, but the flames will continue to vibrate as a single flame would. M. Kastner, for his first experiments, used two flames derived from the combustion of hydrogen gas in suitably constructed burners. The

VOL. LXIX.-ThIRD SERIEs.-No. 5.-MAT, 1875. 
interference of the singing flames is only produced under special conditions. It is certain that the length and the size of the tubes depeuds upon the number of flames. The burners must be of a particular shape; the height of the flames does not exercise much effect upon the phenomenon. From a practical point of view, the numerous experiments effected by M. Kastner during several years, have resulted in the construction of a musical apparatus on an entirely new principle, to which he has given the name of Pyrophone; it may be called a new organ, working by singing flames, or rather by vibrations caused by means of the combustion of these flames. This instrument may be constructed from one octave to a most extended compass.

The British Review humorously remarks that the pyrophone will naturally be valuable in winter, and that in America it has already been recommended to families as a means of warming small apartments, and perhaps an economical stove may be added to it for the culinary exigencies of straightened households.

The pyrophone will have in the future a poetical mission to fill in the music of concerts. A great number of composers and musicians have already admired this new organ performing by the singing of flames, or rather by vibrations determined by means of the combustion of these flames. They think it will be of great advantage in cathedrals and churches, as the most extended compass can be given to the instrument.

I'Année Scientifique, by M. Figuier, declares that the pyrophone is assuredly one of the most original instruments that science has given to instrumental music. In the large pyrophone which M. Kastner has constructed, and which they have not yet been able to bring to London, an artist can produce sounds unknown till the present time, imitating the human voice, but with strange and beautiful tones, capable of producing in religious music the most wonderful effects. So says Le Journal Officiel de l' Exposition de Vienne.

Journals and reviews abroad have unanimously mentioned with praise this new instrument, both from a musical as well as from a scientific point of view.

M. Henri de Parville, in Les Causeries Scientifiques, gives a large space to the consideration of "Singing Flames," and states that "gas music" made its debut at the Vienna Exhibition of 1873. La Nature and La Revue des Sciences, edited by M. Tissandier, believe 
that this new instrument is destined to produce the most remarkable and unexpected effects in the orchestras of lyric theatres and in large concerts. The chandeliers of the theatre, besides serving to light it, may be converted into an immense musical instrument:-

"When the pyrophone is played by a skillful hand, a sweet and truly delicious music is heard; the sounds obtained are of an extraordinary purity and delicacy, recalling the human voice."

The inventor has prepared a large and beautiful singing lustre, with a dozen or fifteen jets, which can be placed in the richest or most comfortable drawing-room. This lustre may be used at concerts or balls, for it can play all the airs in dance music. It will be worked by electricity, so that the performer who plays may be seated in a neighboring room. The effect will be perfectly magical. The future has other surprises for us, for our houses. The most unexpected applications of scientific principles are daily the result of the skillful efforts of learned men.

Without reckoning Professor Tyndall, who is so well known and esteemed on the Continent, many other learned men, English, German, Austrian, (like Schaffgotsch), and Frenchmen have already studied singing flames, but no one had previously thought of studying the effects produced by two or several flames brought together, till M. Kastner, who, by means of delicate combinations and ingenious mechanism, has produced the pyrophone.

Frederic Kastner, the inventor of the pyrophone, showed from his earliest age a very decided taste for scientific pursuits. His parents, whose fine fortune permitted them to satisfy the taste of their son for study, gave him facilities often denied to genius. They frequently traveled; the first thing which arrested his attention was a railway; this pleased him much; he had a passion for locomotives, just as some children have for horses. He was only three years old when he examined the smallest details with a lively feeling of curiosity. Later on, when he tried to reason and explain his impressions, he overwhelmed with questions those who surrounded him, wishing to learn the mechanism of these great machines, and the mysterious force which sers them at work. But what more especially charmed him was, when the train stopped at the station, the fiery aspect of the jets of gas emerging suddenly from the darkness. At this sight he shouted with delight; such was his enthusiasm that he seemed as if 
he would jump out of the arms of those who held him, in order to rush towards the jets of flames, which exercised upon him a sort of fascination.

Steam and gas, in their modern application to locomotion and lighting, were the first scientific marvels which struck the mind and the sense of the child. He studied music under the skillful direction of his father. From the age of fifteen years, in studying gas particularly, his attention was directed to singing flames. The mysteries of electricity were also at this time the object of his study. The researches to which he gave himself up carried him on to invent a novel application of electricity as a motive force. He patented this invention. On the 17th March, 1873, the Baron Larrey, member of the Academy of Sciences of Paris, presented to the Institut de France young Kastner's first memoir on singing flames, which laid down the following new principle:-

"If two flames of a certain size be introduced into a tube made of glass, and if they be so disposed that they reach the third part of the tube's height (measured from the base) the flames will vibrate in unison. This phenomenon continues as long as the flames remain apart; but as soon as they are united the sound ceases."

Passing on to his experiments, M. Kastner thus gives his account:-

"I took a glass tube, the thickness of which was $2 \frac{1}{2}$ millimeters; this tube was 55 centimeters long, and its exterior diameter measured 41 millimeters. Two separate flames of hydrogen gas were placed at a distance of 183 millimeters from the base of the tube. These flames, while separated, gave F natural.

"As soon as the flames are brought together, which is done by means of a very simple mechanism, the sound stops altogether. I $f$, letting the flames remain apart, their position is altered until they reach one-third of the total length of the tube, the sound wili diminish gradually; and it will cease completely if the flames go beyond one-half the length of the tube; under this (one-half the length of the tube) the sound will increase until the flames are brought to onefourth of the tube's total length. 'I'his latter point being reached, the sound will not cease immediately, even if the two flames are placed in contact one with the other; but the two flames, thus united, continue vibrating in the same inanner as a single flame would.

"The interference of the singing flames can only be obtained under certain conditions. It is important that the length of the tubes should be varied according to the number of the flames, the height of which has only a limited action or influence over the phenomenon; 
but the special shape of the burners is a matter of considerable importance.

"These experiments, which I undertook two years ago, induced me to construct a musical instrument, possessing quite a novel sound, which resembles the sound of the human voice. This instrument, which I term the Pyrophone, is formed by three sets of keys (claviers) disposed in a similar manner to that employed for the conjunction of the organ-key tables; a very simple mechanism causes every key of the different sets to communicate with the supply pipes in the glass tubes. As soon as a key is pressed upon, the flames, by separating, create a sound; but when the keys are left untouched, the flames are brought together and the sound stops."

In consequence of this communication a Commission from the Academie des Sciences de Paris was selected for the examination of this curious invention, consisting of Messrs. Jamin, Regnault, and Bertrand, three distinguished members of that academy, who showed a lively interest from a scientific point of view in M. Kastner's discovery. After fresh experiments, M. Kastner has succeeded in substituting the ordinary illuminating gas for hydrogen gas in working this pyrophone, and his friend, the Baron Larrey, was again the interpreter to l'Academie des Sciences of this new discovery, which much facilitates the employment of the luminous musical instrument. M. Kastner thus expresses himself in his new report presented to the Institut de France, 7th Dccomber, 1874:-

"The principal objection which has been made to the working of the pyrophone, is the employment of hydrogen gas. From a practical point of view, this gas presents several inconveniences. It is difficult to prepare; it necessitates the use of gas holders, whose size may be considerable. Besides, there is some dinger in its use. I have, therefore, given up using hydrogen gas, and for a year I have experimented on the means of applying common illuminating gas to the pyrophone, which is always easy to procure. In the first experiments which I attempted with two flames, with illuminating gas, in a glass tube, I was unable to obtain any sound, which proved unmistakably the presence of carbon in the flames. Whilst the sound was produced in a very clear manner with the pure hydrogen gas, that is to say, without there being any solid foreign matter in the flames, it was impossible to make the tube with illuminating gas vibrate, when placing the flames in an identical condition. It was necessary, then, by some means or another to eliminate the carbon, a result at which I arrived by dint of the following method:-

"When the flame of ordinary gas is examined, and this is introduced into a tube made of glass, or of any other material (metal, oileloth, cardboard, etc.), this flame is either illuminating or sounding. 
"When this flame is only illuminating, that is to say, when the air contained in the tube does not vibrate, it presents a lengthened form, and is pointed at the top. Besides, it swells towards the middle, and flickers on the least current of air. On the contrary, when the flame is sounding, that is to say, when the necessary vibrations for the production of sound are produced in the tube, its form is narrow, and large at the top. Whilst the air of the tube vibrates, the flame is very steady. The carbon in a great measure is eliminated as if by some mechanical process.

"Sounding flames proceeding from lighting gas are in effect enveloped in a photosphere which does not exist when the flame is merely luminous. In the latter case the carbon is burnt within the flame, and contributes in a great degree to its illuminating power.

"But when the flames are sounding, the photosphere which surrounds each of them contains an exploding mixture of hydrogen and oxygen which determines the vibrations in the air of the tube.

"To produce the sound in all its intensity, it is necessary and sufficient that the whole of the explosion produced by the particles of oxygen and hydrogen in a given time, should be in agreement with the number of vibrations which correspond to the sound produced by the tube.

"To put these two quantities in harmony, I have thought of increasing the number of flames so as to increase also the number of the explosions from the mixture of oxygen and hydrogen in the photospheres, and thus determine the vibration of the air of the tube. Instead of two flames of pure hydrogen, I put four, five, six, etc., jets of lighting gas in the same tube.

"I have besides observed, that the higher a flame is, the more carbon it contains.

"I have then immediately been obliged to diminish the height of the flames, and consequently to increase the number so that the united surface of all the photospheres may suffice to produce the vibration of the air in the tube.

"The amount of carbon contained in the whole of the small flames will always be much less than the quantity of carbon corresponding to the two large flames necessary to produce the same sound. In this manner I have been able with separated flames to obtain sounds whose tones are as clear as those produced by hydrogen gas. When these flames, or rather when the photospheres which correspond to these flames, are put in contact, the sound instantly ceases. The carbon of lighting gas, when the flames are sounding, is certainly almost entirely eliminated-in fact, it forms upon the interior surface of the sounding tube at and below the height of the flames a very visible deposit of carbon, which increases whilst the air of the tube vibrates. I can now affirm that the Pyrophone is in a condition to act as well with the illuminating gas as with pure hydrogen. The phenomenon 
of interference is produced exactly in the same condition with the two gases, the same flames occupy the same position in the tube, that is the third part of the tube's length measured from the base. In addition to the phenomenon of interference, I believe I shall be able to describe a novel process by aid of which the sound produced by burning flames in a tube can be made to cease.

"Supposing that one or several flames, placed in a tube a third of its height (measured from its base), determine the vibration of the air contained in this tube; if a hole is pierced at the one-third of the tube, counted from the upper end, the sound ceases. This observation might be applied to the construction of a musical instrument, which will be a species of flute, working by singing flames. Such an instrument, from a musical point of view, will be very imperfect, because the sound will not be so promptly or sharply stopped, as when the phenomenon of interference is employed. Iff, instead of making the hole at the third, it is made at the sixth, the sound will not cease, but it will produce the sharp of the same note. In all these experiments I clearly detected the formation of ozone while flames cause the air in the tube to vibrate. The presence of this body can, moreover, be ascertained by chemical re-agents scientifically known."-Given before the Academie des Sciences, 7th December, 1874.

Professor Tyndall, at a lecture on 13th January, at the Royal Institution, showed experiments according to the new principle, with an apparatus of nine flames, which worked during the evening in tubes of different sizes.

Hygroscopic Paper.-Percy Smith has made a series of interesting researches upon the hygroscopic properties of a bibulous paper impregnated with concentrated solution of cobalt chloride. This paper is very sensitive to atmospheric variations, being blue in a dry atmosphere and becoming red when the air becomes humid. $\mathrm{He}$ suspended strips of this paper upon the wall of a room opposite a window opening to the south. The window remained open during the day. By the side of the strips were two thermometers, with wet and dry bulbs. Four observations a day were made, and these were continued for a year. The principal results obtained are given in the annexed table, in which the variations of color from red to blue are designated by the numbers 1 to 10 . It will be seen that when there was a difference of $13^{\circ}$ between the two thermometers, the paper remained entirely blue, and 